COVID-19

\title{
Quality of life and perceived financial implications among otorhinolaryngologists during the COVID-19 pandemic across India
}

\author{
Qualità di vita e impatto economico percepito dalla comunità otolaringoiatrica indiana \\ durante la pandemia da COVID-19
}

\author{
Deviprasad Dosemane ${ }^{1}$, Meera Niranjan Khadilkar ${ }^{1}$, Jayashree Kanthila², Prasanna P. Mithra ${ }^{3}$ \\ ${ }^{1}$ Department of Otorhinolaryngology and Head \& Neck Surgery, Kasturba Medical College, Mangalore, Manipal Academy of \\ Higher Education, Manipal, Karnataka, India - 576104; ${ }^{2}$ Department of Paediatrics, Kasturba Medical College, Mangalore, Manipal \\ Academy of Higher Education, Manipal, Karnataka, India - 576104; ${ }^{3}$ Department of Community Medicine, Kasturba Medical \\ College, Mangalore, Manipal Academy of Higher Education, Manipal, Karnataka, India - 576104
}

\section{SUMMARY}

Objective. The changing trends in medical practice, uncertainties and monetary apprehensions due to the COVID-19 pandemic may influence the sense of well-being among otorhinolaryngologists. The present study was conducted to evaluate quality of life (QOL) and perceived financial implications in otorhinolaryngologists during the COVID-19 pandemic across India.

Methods. A cross-sectional study was carried out among otorhinolaryngology specialists across India using WHOQOL-BREF and Consumer Financial Protection Bureau (CFPB) Financial Well-Being Scale questionnaires on Google Forms, which was kept open for the latter half of July 2020.

Results. A total of 358 responses were obtained; the response rate was $26.64 \%$. Twentyfour percent of respondents worked exclusively in academic settings; $40.22 \%$ of specialists had over 10 years of work experience. Average monthly income in 2019 was between 1-3 lakhs Indian Rupees (INR) in $43.85 \%$, while in $2020,62.57 \%$ of the specialists had an average monthly income of below one lakh INR; this difference was statistically significant $(\mathrm{p}<0.001)$. Mean WHOQOL-BREF scores for physical, psychological, social and environmental domains were $68.8 \pm 1,62.3 \pm 0.75,68.9 \pm 1.17$ and $65.8 \pm 1.01$, respectively; mean CFPB financial well-being scale score was $55.5 \pm 0.66$. QOL and financial well-being were better in otolaryngologists older than 60 years, male specialists and private consultants.

Conclusions. There has been a tremendous impact on quality of life and financial wellbeing among otorhinolaryngologists in India during the COVID-19 pandemic. The study outcome may help otolaryngologists comprehend and perceive the extent to which it has affected their professional and personal lives, and explore ways to face and overcome the situation.

KEY WORDS: CFPB financial well-being scale, financial management, India, otolaryngologists, quality of life, WHOQOL-BREF

\section{RIASSUNTO}

Obiettivo. I cambiamenti della pratica medica, le incertezze e le preoccupazioni inerenti l'impatto economico dovuto alla pandemia COVID-19 possono influenzare negativamente il senso di benessere degli specialisti otorinolaringoiatri. Il presente studio è stato condotto per valutare la qualità della vita $(Q O L)$ e le implicazioni finanziarie percepite dagli otorinolaringoiatri durante la pandemia COVID-19 in tutta l'India.

Metodi. È stato condotto uno studio trasversale tra specialisti di otorinolaringoiatria in tutta l'India utilizzando i questionari WHOQOL-BREF e Consumer Financial Protection Bureau $(C F P B)$ Financial Well-Being Scale su Google Forms, durante la seconda metà di luglio 2020.

Risultati. Abbiamo ricevuto 358 risposte; il tasso di risposta è stato del 26,64\%. Il $24 \%$ degli intervistati ha lavorato esclusivamente in contesti accademici; Il 40,22\% degli spe-
Received: November 5, 2020

Accepted: December 1, 2020

Published online: May 6, 2021

Correspondence

Meera Niranjan Khadilkar

Department of Otorhinolaryngology and Head \& Neck Surgery, Kasturba Medical College, Mangalore, Manipal Academy of Higher Education, Manipal, Karnataka, India - 576104

Tel. +91 8150042608

E-mail: meera.khadilkar@manipal.edu

Funding

None.

Conflict of interest

The Authors declare no conflict of interest.

How to cite this article: Dosemane D, Khadilkar MN, Kanthila J, et al. Quality of life and perceived financial implications among otorhinolaryngologists during the COVID-19 pandemic across India. Acta Otorhinolaryngol Ital 2021;41:289-295. https://doi.org/10.14639/0392-100X-N1229

(C) Società Italiana di Otorinolaringoiatria e Chirurgia Cervico-Facciale

\section{(c) (1) $(9)$}

This is an open access article distributed in accordance with the CC-BY-NC-ND (Creative Commons Attribution-NonCommercial-NoDerivatives 4.0 International) license. The article can be used by giving appropriate credit and mentioning the license, but only for non-commercial purposes and only in the original version. For further information: https:// creativecommons.org/licenses/by-nc-nd/4.0/deed.en 
cialisti aveva più di dieci anni di esperienza lavorativa. Il reddito mensile medio nel 2019 era compreso tra 100 mila e 300 mila rupie indiane (INR) nel 43,85\%, mentre nel 2020, il 62,57\% degli specialisti aveva un reddito mensile medio inferiore a 100 mila INR; questa differenza era statisticamente significativa $(p<0,001)$. I punteggi WHOQOL-BREF medi per i domini fisico, psicologico, sociale e ambientale erano rispettivamente 68,8 $\pm 1,62,3 \pm 0,75,68,9 \pm 1,17$ e 65,8 $\pm 1,01$; Il punteggio medio della scala del benessere finanziario CFPB era 55,5 $\pm 0,66$. La qualità della vita e il benessere finanziario erano migliori negli otorinolaringoiatri di età superiore ai 60 anni, negli specialisti maschi e nei consulenti privati.

Conclusione. Durante la pandemia COVID-19 c'è stato un impatto enorme sulla qualità della vita e sulal stabilità economica tra gli otorinolaringoiatri in India. Il risultato dello studio può aiutare gli otorinolaringoiatri a comprendere e percepire fino a che punto il COVID-19 ha influito sulla loro vita professionale e personale ed esplorare modi e mezzi per affrontare e superare la situazione.

PAROLE CHIAVE: scala del benessere finanziario CFPB, gestione finanziaria, India, otorinolaringoiatri, qualità della vita, WHOQOL-BREF

\section{Introduction}

The novel coronavirus disease (COVID-19) pandemic has destabilised every facet of medical care in a short period ${ }^{1}$. Though every healthcare worker has some risk of exposure, it is predominantly marked in those treating patients undergoing aerosol-generating or mucosal procedures ${ }^{2}$, such as otolaryngology specialists and maxillofacial and head and neck surgeons. Although all protective precautions are to be adhered to, there can be chances of altered comfort level, fear, etc. Therefore, sustaining a balance between physical health and mental health is of utmost importance to perform with optimal lucidity ${ }^{3}$.

It now requires healthcare workers to find newer methods of providing safe healthcare while keeping patient outcomes and valuable resources in mind ${ }^{4}$. This changing trend in medical practice and the uncertainties can influence the quality of life of healthcare professionals. Also, the bearing of monetary apprehensions on the performance and wellbeing of healthcare providers must not be undervalued ${ }^{5}$.

Patients with upper respiratory infections who were earlier attending otorhinolaryngology clinics are now triaged to COVID-19/ fever screening portals. The American Academy of Otolaryngology-Head \& Neck Surgery has endorsed otolaryngologists to postpone elective cases to permit better safety of healthcare workers and patients, conserve essential personal protective equipment (PPE) and magnify the capacity of hospitals and treatment centres during the pandemic ${ }^{4}$. Because of these circumstances, the income of otolaryngologists is likely to be affected significantly.

There are limited studies on health care professionals in the literature, and otolaryngologists in specific, regarding the effect of this pandemic on mental health and clinical practice. Similarly, in India, none of the studies have focused on the financial consequences in otolaryngologists. The present study was performed to evaluate the quality of life (QOL) and perceived financial implications in otorhinolaryngologists during the COVID-19 pandemic across India.

\section{Materials and methods}

This cross-sectional study was carried out among otorhinolaryngology specialists in institutions and/or private settings across India between June and July 2020. After obtaining Institutional Ethics Committee (IEC) approval from Kasturba Medical College, Mangalore (Reference number IEC KMC MLR 07/2020/211), participants were contacted and enlightened about the study objectives using Google Forms through WhatsApp groups, social media (Facebook) and e-mails. They were assured of anonymity and confidentiality of the information collected from them. Digital consent was obtained from each participant with Google Forms. The data were collected using WHOQOL-BREF ${ }^{6}$ and Consumer Financial Protection Bureau (CFPB) Financial Well-Being Scale questionnaires ${ }^{7}$ on Google Forms, which were distributed via the same platforms. Junior residents undergoing training in otorhinolaryngology were excluded from the study. The survey was kept open from 15 July 2020 for 2 weeks to reduce the bias of the outcome at a particular point. Basic demographic details such as age, gender, state/union territory, faculty position, practice setting, number of years of work experience in otorhinolaryngology and average monthly income for the years 2019 and 2020 were also obtained.

WHOQOL-BREF questionnaire contains 26 items and 4 domains. The physical domain comprises daily activities, the necessity of medications, fatigue and energy, mobility, discomfort and pain, the capacity to work and sleep. The psychological domain takes into account bodily appearance and image, positive plus negative feelings, selfesteem, belief and spirituality, thinking ability, concentration, recollection and learning. The social domain includes interpersonal relationships, support from friends and sexual activity. Sense of security and safety, accessibility, monetary resources, quality of healthcare, home and physical environment, leisure activities, transport and prospects for obtaining additional information and skills, make up the environmental domain. The domain scores provide an insight into the quality of life of an individual in each domain. The scores are represented positively, meaning greater scores 
signify a better quality of life. Scores of items within each domain are added up to compute the raw domain score, which is then transformed to a $0-100$ scale $^{6}$.

CFPB Financial well-being scale questionnaire comprises 10 questions. The total response value is obtained by adding up individual responses. This is converted to a CFPB Financial Well-Being Scale score depending on the respondent's age group, and whether the questionnaire was self-administered. The final score is a standardised number between 0 and 100, which depicts an individual's essential measure of financial well-being. A higher score represents a better degree of estimated financial well-being ${ }^{7}$.

The confidentiality of information was strictly maintained. The collected data were coded and entered into Microsoft Excel for Windows and analysed using Jamovi 1.1.9.0 software, Sydney, Australia. Results were expressed as proportion and summary measures using appropriate tables. Individual WHOQOL-BREF domain scores and CFPB Financial well-being scale score were compared with the demographic variables using linear regression study. WHOQOL-BREF domain scores were compared with the CFPB Financial well-being scale score using Pearson's correlation coefficient test. A comparison of average monthly income for the years 2019 and 2020 was done with Chi-square test. A pvalue of below 0.05 was regarded as statistically significant.

\section{Results}

Three hundred and fifty-eight responses from 24 states and 2 union territories of India were obtained from 1344 otorhinolaryngologists contacted with a response rate of $26.64 \%$. Age ranged from 26 years to 70 years, with a mean and median age of 40 and 37 years, respectively. There were 239 males (66.8\%) and 119 females (33.2\%), with a male/female ratio of 2.01. The majority of the respondents worked in Karnataka (39.1\%) state, followed by Maharashtra (9.8\%) and Kerala (7.5\%) (Tab. I). Most of the specialists worked as private consultants (45.8\%). Twenty-four percent of respondents worked exclusively in academic settings. Over 10 years of work experience was reported by $40.22 \%$ of specialists. In the majority $(43.85 \%)$, average monthly income in 2019 was between one to three lakhs Indian Rupees (INR), while in 2020, $62.57 \%$ of the specialists had an average monthly income of below one lakh INR (Fig. 1). Chi-square test used to compare average monthly income for the years 2019 and 2020 was highly statistically significant $\left(\mathrm{X}^{2}=165, \mathrm{p}<0.001\right)$.

Mean WHOQOL-BREF scores for the physical, psychological, social and environmental domains were $68.8 \pm 1$, $62.3 \pm 0.75,68.9 \pm 1.17$ and $65.8 \pm 1.01$, respectively. The mean CFPB financial well-being scale score was $55.5 \pm 0.66$
Table I. Geographical distribution of respondents.

\begin{tabular}{|c|c|c|}
\hline State/Union Territory in India & Count & Proportion \\
\hline \multicolumn{3}{|l|}{ South India } \\
\hline Karnataka & 140 & $39.1 \%$ \\
\hline Kerala & 27 & $7.5 \%$ \\
\hline Andhra Pradesh & 23 & $6.4 \%$ \\
\hline Tamil Nadu & 20 & $5.6 \%$ \\
\hline Telangana & 12 & $3.4 \%$ \\
\hline Pondicherry & 2 & $0.6 \%$ \\
\hline TOTAL & 224 & $62.6 \%$ \\
\hline \multicolumn{3}{|l|}{ Central India } \\
\hline Maharashtra & 35 & $9.8 \%$ \\
\hline Gujarat & 13 & $3.6 \%$ \\
\hline Madhya Pradesh & 4 & $1.1 \%$ \\
\hline Chhattisgarh & 4 & $1.1 \%$ \\
\hline Odisha & 3 & $0.8 \%$ \\
\hline West Bengal & 3 & $0.8 \%$ \\
\hline Goa & 2 & $0.6 \%$ \\
\hline TOTAL & 64 & $17.8 \%$ \\
\hline \multicolumn{3}{|l|}{ North India \& North-East India } \\
\hline Rajasthan & 17 & $4.7 \%$ \\
\hline Delhi & 16 & $4.5 \%$ \\
\hline Uttar Pradesh & 14 & $3.9 \%$ \\
\hline Assam & 5 & $1.4 \%$ \\
\hline Haryana & 5 & $1.4 \%$ \\
\hline Sikkim & 3 & $0.8 \%$ \\
\hline Punjab & 3 & $0.8 \%$ \\
\hline Uttarakhand & 2 & $0.6 \%$ \\
\hline Manipur & 1 & $0.3 \%$ \\
\hline Bihar & 1 & $0.3 \%$ \\
\hline Jharkhand & 1 & $0.3 \%$ \\
\hline Nagaland & 1 & $0.3 \%$ \\
\hline Meghalaya & 1 & $0.3 \%$ \\
\hline TOTAL & 70 & $19.6 \%$ \\
\hline
\end{tabular}

(Tab. II). WHOQOL-BREF domain scores were compared with the CFPB financial well-being scale score and were significant ( $\mathrm{p}<0.001$ ) (Tab. III). WHOQOL-BREF scores for all four domains, as well as CFPB financial well-being scale score, were higher in otorhinolaryngologists above 60 years of age; WHOQOL-BREF score for the social domain was highest in the age group of 41-50 years. Males were found to have a better quality of life and CFPB financial well-being scores, and this difference was statistically significant. Associate professors were found to have the best quality of life and CFPB financial well-being scale scores among all faculty positions. Physical, psychological and environmental domain scores, as well as financial well-being, were highest 


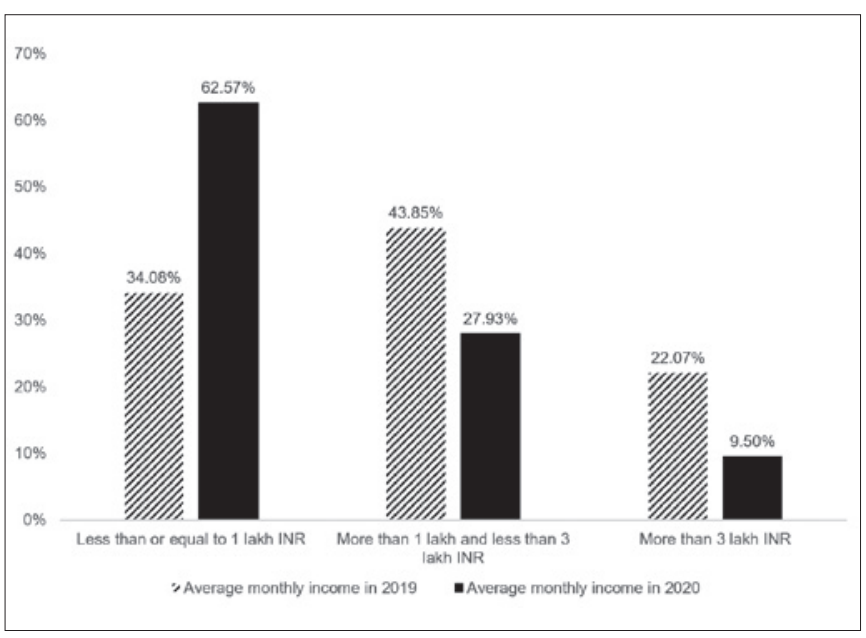

Figure 1. Graphical representation of average monthly income in the years 2019 and 2020 in otorhinolaryngologists in India.

in otorhinolaryngologists working in private settings, while social domain score was the highest in government hospital specialists. No statistical significance was found between domain scores, scores of CFPB financial well-being scale and practice setting. Quality of life domain scores and financial well-being scores were highest in specialists with experience of over 10 years post-specialisation and those with an average monthly income above three lakh INR (Tab. IV).

\section{Discussion}

COVID-19 is affecting people from all walks of life worldwide, including healthcare workers. The disease is highly contagious, predominantly acquired through respiratory droplets. Therefore, healthcare providers such as otorhinolaryngologists managing patients with aerodigestive tract related diseases are the most susceptible to infection. The first physician to succumb to COVID-19 was an otolaryngologist from Wuhan, China on 25 January $2020^{5}$.

The number of COVID-19 cases and fatalities is rapidly escalating in India; physicians have also succumbed to the virus, making the situation grim. The Medical Group Management Association reported that the pandemic has adversely affected finances in $97 \%$ of 724 medical practices that were surveyed ${ }^{8}$.

The WHOQOL-BREF questionnaire was developed to generate a tool that would assess the quality of life and apply across all ethnic groups. The initiative comes from a requirement of a genuine measure pertinent internationally and an assurance to the sustained promotion of a universal approach to healthcare. The questionnaire comprises 26 questions to enable assessment of physical, psychological, social, environmental domains ${ }^{6}$.

The Consumer Financial Protection Bureau steered a laborious research attempt to develop a consumer-driven description of financial well-being, thus enabling researchers worldwide with a consistent, accurate and accessible technique of determining financial well-being and perceive the point to which one's financial status and capacity offer them a sense of security and liberty of choice. Thus, a 10 -item scale was developed ${ }^{7}$. No investigations assessing the financial welfare of healthcare providers using CFPB financial well-being scale score have been conducted to the best of our understanding.

In the present study, otorhinolaryngology specialists above the age of 60 years were found to be the most financial-

Table II. WHOQOL-BREF domain scores and CFPB financial well-being scale score.

\begin{tabular}{|c|c|c|c|c|c|}
\hline Parameters & Mean & Median & Standard deviation & Minimum & Maximum \\
\hline \multicolumn{6}{|l|}{ WHOQOL-BREF domain score } \\
\hline Physical & 68.80 & 69 & 18.9 & 6 & 100 \\
\hline Psychological & 62.30 & 63 & 14.1 & 6 & 94 \\
\hline Social & 68.90 & 69 & 22.1 & 0 & 100 \\
\hline Environmental & 65.80 & 69 & 19.1 & 6 & 100 \\
\hline CFPB financial well-being scale score & 55.50 & 55 & 12.6 & 14 & 95 \\
\hline
\end{tabular}

Table III. Comparison of WHOQOL-BREF domain scores with CFPB financial well-being scale score.

\begin{tabular}{lccccc} 
& \multicolumn{3}{c}{ WHOQOL- BREF domain score } \\
& & Physical & Psychological & Social & Environmental \\
CFPB financial well-being scale & Pearson's correlation coefficient $r$ & 0.535 & 0.494 & 0.453 & 0.657 \\
score & p-value & $<0.001^{*}$ & $<0.001^{*}$ & $<0.001^{*}$ & $<0.001^{*}$ \\
\hline
\end{tabular}

Highly statistically significant. 
Table IV. Comparison of various parameters with mean WHOQOL-BREF domain scores and mean CFPB financial well-being scale score.

\begin{tabular}{|c|c|c|c|c|c|c|}
\hline & $\mathrm{N}(\%)$ & $\begin{array}{l}\text { Mean physical } \\
\text { score }\end{array}$ & $\begin{array}{l}\text { Mean } \\
\text { psychological } \\
\text { score }\end{array}$ & Mean social score & $\begin{array}{l}\text { Mean } \\
\text { environmental } \\
\text { score }\end{array}$ & $\begin{array}{c}\text { Mean CFPB } \\
\text { financial well-being } \\
\text { scale score }\end{array}$ \\
\hline \multicolumn{7}{|l|}{ Age } \\
\hline $31-40$ & 177 (49.44\%) & $68.18 \pm 18.38$ & $63.43 \pm 17.08$ & $68.28 \pm 22.51$ & $63.64 \pm 18.5$ & $54.03 \pm 12.67$ \\
\hline $41-50$ & 82 (22.91\%) & $69 \pm 19.72$ & $66.63 \pm 19.19$ & $72.84 \pm 21.66$ & $67.3 \pm 17.82$ & $56.85 \pm 10.92$ \\
\hline p-value & & $0.027^{\#}$ & 0.109 & 0.114 & $<0.001^{\star}$ & $<0.001^{\star}$ \\
\hline \multicolumn{7}{|l|}{ Gender } \\
\hline Male & $239(66.80 \%)$ & $70.03 \pm 18.29$ & $67.86 \pm 17.15$ & $68.92 \pm 20.96$ & $66.64 \pm 18.89$ & $56.08 \pm 12.96$ \\
\hline Female & $113(33.20 \%)$ & $66.45 \pm 19.98$ & $58.54 \pm 18.98$ & $68.84 \pm 24.18$ & $64.24 \pm 19.60$ & $54.34 \pm 11.69$ \\
\hline Professor & $46(12.80 \%)$ & $67.07 \pm 18.78$ & $68 \pm 16.81$ & $70.93 \pm 20.55$ & $69.85 \pm 17.45$ & $58.7 \pm 10.45$ \\
\hline Associate Professor & 20 (5.60\%) & $73.7 \pm 18.66$ & $71.1 \pm 18.73$ & $76.55 \pm 18.96$ & $70.1 \pm 14.14$ & $59.05 \pm 11.61$ \\
\hline Assistant Professor & $51(14.20 \%)$ & $68.39 \pm 20.54$ & $62.25 \pm 20.36$ & $67.76 \pm 26.4$ & $62.84 \pm 18.84$ & $53.67 \pm 11.23$ \\
\hline Senior Resident & 77 (21.50\%) & $64.32 \pm 16.59$ & $60.27 \pm 15.42$ & $64.17 \pm 19.22$ & $61.48 \pm 18.89$ & $52.7 \pm 12.08$ \\
\hline$p$-value & & 0.081 & 0.31 & 0.144 & 0.059 & $0.043^{\#}$ \\
\hline \multicolumn{7}{|l|}{ Practice setting } \\
\hline Academic setting & 85 (23.74\%) & $66.35 \pm 17.67$ & $63.06 \pm 16.59$ & $66.28 \pm 20.97$ & $64.88 \pm 17.22$ & $54.66 \pm 12.12$ \\
\hline Private setting & 239 (66.76\%) & $69.83 \pm 19.32$ & $65.4 \pm 18.75$ & $69.34 \pm 22.71$ & $66.32 \pm 19.43$ & $55.79 \pm 13.02$ \\
\hline $\begin{array}{l}\text { Government } \\
\text { hospital }\end{array}$ & $34(9.50 \%)$ & $68.03 \pm 19$ & $64.53 \pm 19.27$ & $72.24 \pm 19.81$ & $64.88 \pm 21.87$ & $55.59 \pm 10.46$ \\
\hline
\end{tabular}

"Statistically significant; " Highly statistically significant.

ly stable (CFPB financial well-being scale mean score of $70.12 \pm 9.83$ ) and had the highest scores among three of the 4 domains of WHOQOL-BREF $(76.59 \pm 18.01$, $72.12 \pm 13.69,81.06 \pm 12.63$ in physical, psychological and environmental domains respectively), with statistical significance for physical and environmental domains and financial well-being. Quality of life and financial well-being was also the highest in respondents with over 10 years of work experience post-specialisation (mean WHOQOLBREF score of $71.83 \pm 18.51$ for physical, $68.8 \pm 17.48$ for psychological, $72.6 \pm 20.86$ for social, $70.31 \pm 17.58$ for environmental domains, and mean CFPB financial wellbeing scale score of $58.4 \pm 11.88$ ), with statistical significance. This emphasises the fact that with advancing age, there is greater monetary stability, contentment, satisfaction and also an enhanced ability in managing professional and financial commitments. The frontline COVID-19 healthcare providers typically belong to the younger strata, who are burdened by prolonged working hours, stressful lifestyle, fear of contracting the disease and lesser income. Moreover, unsettled duty schedules, unconventional work patterns and unfamiliar patient care units have taken a toll on the physical, emotional and social well-being. This also explains the findings of the lowest quality of life (mean scores of $64.32 \pm 16.59,60.27 \pm 15.42,64.17 \pm 19.22$, $61.48 \pm 18.89$ in the 4 domains of WHOQOL-BREF, respectively) and financial well-being $(52.7 \pm 12.08)$ in the younger respondents mainly comprising senior residents, 
compared with other faculty positions and private practitioners. Statistical significance was noted between the CFPB financial well-being score and all cadres of otolaryngologists. Liang and co-authors studied mental well-being in medical staff during COVID-19 pandemic and found that depression and anxiety were more prevalent in the younger frontline healthcare workers ${ }^{9}$. Another study by Lai et al. in healthcare workers treating COVID-19 patients showed that mental health was most affected in junior and intermediate level staff ${ }^{10}$. However, it is presumed that healthcare professionals were relatively comfortable and tuned in to their regular working conditions prior to the pandemic.

Quality of life was superior in men when compared to women respondents (mean WHOQOL-BREF scores of $70.03 \pm 18.29,67.86 \pm 17.15,68.92 \pm 20.96,66.64 \pm 18.89$ for the 4 domains respectively); so was the CFPB financial well-being scale score (mean score of $56.08 \pm 12.96$ ). Extremely high statistical significance for 3 of the 4 WHOQOL-BREF domains and financial well-being ( $\mathrm{p}$-value $<0.001$ ) was found between male and female respondents. This can be attributed to the fact that women have more domestic responsibilities, and are constantly subjected to societal, family and moral pressures. A study by Civantos et al. to assess mental healthiness in otolaryngologists in the course of the COVID-19 pandemic revealed women suffered from a greater amount of distress and burnout ${ }^{2}$. Dewey and co-authors provided practical suggestions to boost the clinical workforce during the COVID-19 pandemic. These include recognising concerns, fixed work hours, providing ample resources and adequate PPE, engaging in wellness activities, promoting spiritual resilience ${ }^{11}$.

Specialists working exclusively in academic settings were found to have a lower quality of life (mean scores of $66.35 \pm 17.67,63.06 \pm 16.59,66.28 \pm 20.97,63.71 \pm 19.55)$ and financial well-being $(63.71 \pm 19.55)$ compared with doctors working in private sectors. Besides patient care, faculty working in educational institutions are weighed down by undergraduate, postgraduate teaching, research work and other academic activities. Financial well-being was greatest in the private sector specialists $(57.78 \pm 13.75)$, which is expected since private sectors generate more revenue. It was noticed that the quality of life in doctors with private practice had only slightly higher WHOQOLBREF domain scores. The plausible explanation could be that practitioners running private establishments are under continual stress concerning the smooth functioning of the setup, dealing with medico-legal aspects and independent decision-making, in contrast to specialists working in academic institutions, who could seek guidance and support from their peers and colleagues.

Quality of life was higher in social and physical domains (mean WHOQOL-BREF score of $68.9 \pm 1.17$ and $68.8 \pm 1$, respectively) compared to psychological and environmental domains $(62.3 \pm 0.75$ and $65.8 \pm 1.01$, respectively). An improved sense of health consciousness, enhanced tools of audio and video communication and social media have helped otolaryngologists maintain a balance between physical and social domains. However, mental well-being remains a matter of concern. The emotional toll upon clinicians is demanding; unexpected circumstances inexorably bring about extreme moral strain. Self-care and well-being of practitioners and observing for indicators of burnout are critical to stay adequately irrepressible and endure challenges in these tough times ${ }^{1}$. Fitness activities and yoga should be promoted to enhance the physical and emotional wellness of otolaryngologists to combat stress.

The present study showed that the average monthly income of otorhinolaryngologists drastically dropped during the COVID-19 pandemic compared to 2019. The number of respondents earning over 3 lakh INR and between 1 and 3 lakh INR halved over one year, thus increasing the number of specialists in the less than 1 lakh INR bracket. This was also found to be statistically significant. The average CFPB financial well-being scale score was $55.5 \pm 0.66$. Doctors working in academic institutions have faced a reduction in their remuneration; elective otorhinolaryngology procedures and surgeries have been postponed or cancelled with the onset of the pandemic owing to the risk of exposure to infection.

The greatest number of respondents were from the southern states of Karnataka, Kerala and central state of Maharashtra. Incidentally, the number of COVID-19 infected cases was also greater (112,504 in Karnataka and 400,651 in Maharashtra, respectively) ${ }^{12}$. Also, a paradigm shift was noted in Gross State domestic product (GSDP) in these states with the onset of the pandemic ${ }^{13}$.

Many otorhinolaryngologists are keenly waiting to restart their pre-pandemic daily routine ${ }^{1}$. With resurgent India galloping towards universal digitisation in all fields, telemedicine should be encouraged and implemented effectively for efficient healthcare delivery to the public and financial recovery of the healthcare setup.

To the best of our knowledge, there are no studies in medical literature determining the quality of life in otorhinolaryngology specialists, nor has the financial well-being been analysed. The response rate $(26.64 \%)$ was lower than expected, which may be attributed to the short time frame of two weeks that the survey was kept open. The changing trends in COVID-19 infected cases, and the fluctuation in individual response to the questionnaire prompted us to limit data collection for two weeks only. The figure may not be representative of the entire population of otolaryngologists 
in India, although as the majority of the respondents belong to the states of Karnataka and Maharashtra, where a lot of otolaryngologists are based, the data may be considered archetypal. The findings of the study may be generalised to some extent, assuming that the pre-pandemic situation was stable with regard to social and economic aspects. Limitations of the study include a comparison with the quality of life before the COVID-19 pandemic which was not assessed, and parameters attributable to COVID-19 disease such as working hours before and during the pandemic, availability of personal protective equipment and training, magnitude of the pandemic were not studied. State-wise comparison of quality of life and financial welfare is recommended, as disease burden varies in the different regions of the country.

\section{Conclusions}

COVID-19 has had a tremendous impact on the quality of life and financial well-being of otorhinolaryngologists in India. The treating specialists may be fatigued, but the pandemic is most likely here to stay. Since the profession demands that patient service cannot be compromised, a watchful balance is required between risk of exposure and patient care. The outcome of the study may help otolaryngologists comprehend and perceive the extent to which the pandemic has affected their professional and personal lives, and explore ways and means to face and overcome the situation.

\section{Acknowledgements}

The authors are grateful to all the otorhinolaryngologists from India for participating in the study. We acknowledge Dr. Pooja D. Nayak, Dr. Bhavya B.M., Dr. Prishni Dutta for helping with data collection. We are thankful to Dr. Urmila Khadilkar and Dr. N.P. Khadilkar for proofreading the manuscript.

\section{References}

1 Shuman AG. Navigating the ethics of COVID-19 in otolaryngol- ogy. Otolaryngol Head Neck Surg 2020;162:811-812. https://doi. org/10.1177/0194599820920850

2 Civantos AM, Byrnes Y, Chang C, et al. Mental health among otolaryngology resident and attending physicians during the COVID-19 pandemic: national study. Head Neck 2020;42:1597-1609. https://doi. org/10.1002/hed.26292

3 Balasubramanian A, Paleri V, Bennett R, et al. Impact of COVID-19 on the mental health of surgeons and coping strategies. Head Neck 2020;42:1638-1644. https://doi.org/10.1002/hed.26291

4 Brody RM, Nicolli E, Bur AM, et al. Changes in head and neck oncologic practice during the COVID-19 pandemic. Head Neck 2020;42:1448-1453. https://doi.org/10.1002/hed.26233

5 Kowalski LP, Sanabria A, Ridge JA, et al. COVID-19 pandemic: effects and evidence-based recommendations for otolaryngology and head and neck surgery practice. Head Neck 2020;42:1259-1267. https://doi.org/10.1002/hed.26164

6 World Health Organization. WHOQOL-BREF Introduction, Administration, Scoring and Generic Version of the Assessment Field Trial. Geneva: World Health Organization; December 1996. https://www. who.int/mental_health/media/en/76.pdf. Accessed August 2020.

7 Consumer Financial Protection Bureau. Measuring financial wellbeing - A guide to using the CFPB Financial Well-Being Scale. Washington: Consumer Financial Protection Bureau; December 2015. https://files.consumerfinance.gov/f/201512_cfpb_financial-well-beinguserguide-scale.pdf. Accessed August 2020

8 Rubin R. COVID-19's crushing effects on medical practices, some of which might not survive. JAMA 2020;324:321-323. https://doi. org/10.1001/jama.2020.11254

9 Liang Y, Chen M, Zheng X, et al. Screening for Chinese medical staff mental health by SDS and SAS during the outbreak of COVID-19. J Psychosom Res 2020;133:110102. https://doi.org/10.1016/j.jpsychores.2020.110102

10 Lai J, Ma S, Wang Y, et al. Factors associated with mental health outcomes among health care workers exposed to Coronavirus disease 2019. JAMA Netw Open 2020;3:e203976. https://doi.org/10.1001/ jamanetworkopen.2020.3976

11 Dewey C, Hingle S, Goelz E, et al. Supporting clinicians during the COVID-19 pandemic. Ann Intern Med 2020;172:752-753. https://doi. org/10.7326/M20-1033

12 PRS Legislative Research. COVID-19 - Compare States. New Delhi: PRS Legislative Research; June 2020. https://prsindia.org/covid-19/ cases/statewisecomparison. Accessed August 2020.

13 Deccan Herald. Covid-19: GDP of states to contract 1.4-14.3\% in FY21, says report. Mumbai: Deccan Herald; June 2020. https:// www.deccanherald.com/business/economy-business/covid-19-gdpof-states-to-contract-14-143-in-fy21-says-report-855042.html. Accessed August 2020. 